\title{
Arctic gypsum endoliths: a biogeochemical characterization of a viable and active microbial community
}

\author{
L. A. Ziolkowski ${ }^{1, *}$, N. C. S. Mykytczuk ${ }^{2}$, C. R. Omelon ${ }^{3}$, H. Johnson ${ }^{4}$, L. G. Whyte ${ }^{2}$, and G. F. Slater ${ }^{1}$ \\ ${ }^{1}$ Department of Geography and Earth Science, McMaster University, Hamilton, ON L8S-2S4, Canada \\ ${ }^{2}$ Department of Natural Resource Sciences, McGill University, Montréal, QC H9X-3V9, Canada \\ ${ }^{3}$ Department of Geological Sciences, The University of Texas at Austin, Austin, TX 78712, USA \\ ${ }^{4}$ Department of Earth and Ocean Sciences, University of Victoria, Victoria, BC V8P 5C2, Canada \\ *now at: Department of Earth and Ocean Sciences, University of South Carolina, Columbia, SC 29208, USA
}

Correspondence to: L. A. Ziolkowski (lorized@gmail.com)

Received: 11 January 2013 - Published in Biogeosciences Discuss.: 8 February 2013

Revised: 4 October 2013 - Accepted: 22 October 2013 - Published: 27 November 2013

\begin{abstract}
Extreme environmental conditions such as those found in the polar regions on Earth are thought to test the limits of life. Microorganisms living in these environments often seek protection from environmental stresses such as high UV exposure, desiccation and rapid temperature fluctuations, with one protective habitat found within rocks. Such endolithic microbial communities, which often consist of bacteria, fungi, algae and lichens, are small-scale ecosystems comprised of both producers and consumers. However, the harsh environmental conditions experienced by polar endolithic communities are thought to limit microbial diversity and therefore the rate at which they cycle carbon. In this study, we characterized the microbial community diversity, turnover rate and microbe-mineral interactions of a gypsum-based endolithic community in the polar desert of the Canadian high Arctic. 16S/18S/23S rRNA pyrotag sequencing demonstrated the presence of a diverse community of phototrophic and heterotrophic bacteria, archaea, algae and fungi. Stable carbon isotope analysis of the viable microbial membranes, as phospholipid fatty acids and glycolipid fatty acids, confirmed the diversity observed by molecular techniques and indicated that present-day atmospheric carbon is assimilated into the microbial community biomass. Uptake of radiocarbon from atmospheric nuclear weapons testing during the 1960s into microbial lipids was used as a pulse label to determine that the microbial community turns over carbon on the order of $10 \mathrm{yr}$, equivalent to $4.4 \mathrm{~g} \mathrm{C} \mathrm{m}^{-2} \mathrm{yr}^{-1}$ gross primary productivity. Scanning electron microscopy (SEM) micrographs indicated that mechan-
\end{abstract}

ical weathering of gypsum by freeze-thaw cycles leads to increased porosity, which ultimately increases the habitability of the rock. In addition, while bacteria were adhered to these mineral surfaces, chemical analysis by micro-X-ray fluorescence $(\mu-\mathrm{XRF})$ spectroscopy suggests little evidence for microbial alteration of minerals, which contrasts with other endolithic habitats. While it is possible that these communities turn over carbon quickly and leave little evidence of microbe-mineral interaction, an alternative hypothesis is that the soluble and friable nature of gypsum and harsh conditions lead to elevated erosion rates, limiting microbial residence times in this habitat. Regardless, this endolithic community represents a microbial system that does not rely on a nutrient pool from the host gypsum cap rock, instead receiving these elements from allochthonous debris to maintain a more diverse and active community than might have been predicted in the polar desert of the Canadian high Arctic.

\section{Introduction}

All life on Earth lives within certain physical bounds. For life to thrive it requires liquid water, an energy source and organic molecules. Polar regions on Earth are one place where these limits of life are tested as air temperatures that average well below $0^{\circ} \mathrm{C}$ limit the availability of liquid water and therefore microbial metabolism (Friedmann et al., 1987; Omelon et al., 2006). Additionally, there are many months without any solar radiation, the primary energy source for such communities 
via photosynthetic activity, and thus both energy and associated organic molecules are limited. In such extreme conditions, microbes find protective niches within the rocks as endolithic communities.

Endolithic communities are now understood to be true ecosystems (Walker and Pace, 2007a) where bacteria, algae, and fungi play vital roles in many biogeochemical processes including metal cycling, rock weathering, soil development and authigenic mineral formation. Primary productivity within most endolithic communities is driven by photoautotrophy (Friedmann, 1982; Friedmann et al., 1981, 1987; Friedmann and Ocampo-Friedmann, 1984; Kappen et al., 1981; Matthes et al., 2001; Nienow et al., 1988; Omelon et al., 2006; Vestal, 1988a, b; Vestal et al., 1984). Globally, these endolithic communities colonize rocks of many different lithologies (Boison et al., 2004; de los Ríos et al., 2005; Dong et al., 2007; Ferris and Lowson, 1997; Friedmann, 1980; Hughes and Lawley, 2003; Norris and Castenholz, 2006; Parnell et al., 2004; Sigler et al., 2003; Wierzchos et al., 2006, 2013), with the basic requirement being mineral translucence or the presence of cracks of fractures to allow light into the endolithic habitat for photoautotrophic microorganisms.

Endolithic microbial communities inherently involve microbe-mineral interactions (Blackhurst et al., 2004; Büdel et al., 2004; de los Ríos et al., 2003; Ferris and Lowson, 1997; Johnston and Vestal, 1993, 1989, 1986; Omelon et al., 2007; Sterflinger, 2000; Wierzchos et al., 2003). Microbial colonization of the pores and cracks of rocks induce bioweathering, most notably observed as both subsurface metal mobilization and rock surface exfoliation patterns (Friedmann, 1982). Climate plays a role in these interactions, with warmer temperatures increasing rates of metabolic activity and subsequent accelerated weathering rates in the presence of water. The degree of microbial activity has been linked to the weathering rates of endolithic habitats such as in sandstone formations of South Africa where rock weathering is driven by cyanobacterial alkalization and subsequent dissolution of silica cements (Büdel et al., 2004).

Endolithic microbial communities are typically dominated by either cyanobacterial phototrophs (i.e., Chroococcidiopsis sp., Anabaena sp.) and bacterial heterotrophs (i.e., Actinobacteria and Proteobacteria), or by lichenizing fungi (lichenizing Ascomycetes) and their commensal algal symbionts (i.e., Trebouxia sp.), and, on occasion, with a small population of archaea (Friedmann, 1982; Walker and Pace, 2007b; Pointing et al., 2009). Molecular studies of various endolithic communities have demonstrated that these are among the simplest microbial ecosystems known (Walker and Pace, 2007b, and references therein). The extreme nature of endolithic habitats necessitates a community of highly adapted microorganisms (a common global metacommunity) that can survive specific physical, chemical and environmental conditions of the host rock and climate (Friedmann, 1982; Walker and Pace, 2007b). Polar deserts in particular are thought to be more limiting on possible microbial habitation of lithic substrates due to low temperatures, low water availability, high UV radiation and seasonal limitation of solar radiation necessary for primary production (Omelon et al., 2008).

As such, microbial activity of endolithic communities within polar environments is low and is thought to be potentially cycling carbon on geologic timescales (Bonani et al., 1988; Vestal and Johnston, 1990; Sun and Friedmann, 1999). Activity within these endolithic communities can be measured using a number of techniques, from culture-based methods, to stable isotope probing in the field, to quantifying microbe-mineral alteration of the host rock. Most estimates of productivity within endolithic communities are estimated by measuring the incorporation of an isotopically enriched compound into an uncultivated microorganism either in a laboratory setting or the field (Vestal, 1988a; Cockell and Stokes, 2004; Wong et al., 2009). While monitoring the incorporation of an isotopic label into organisms allows for the detection of activity even when there is limited activity, these studies typically require altering the environmental conditions. In slowly cycling communities such as polar endolithic communities, natural abundance radiocarbon can be used to assess the activity of the community. Nuclear weapons testing in the 1960 s nearly doubled the ${ }^{14} \mathrm{C} /{ }^{12} \mathrm{C}$ ratio in the Northern Hemisphere atmospheric $\mathrm{CO}_{2}$. After testing was banned in 1963 , the amount of ${ }^{14} \mathrm{C}$ in the atmospheric decreased over time due to uptake by the terrestrial and oceanic carbon pools (Naegler and Levin, 2006; Levin and Hesshaimer, 2000). Since the amount of radiocarbon decay of ${ }^{14} \mathrm{C}$ is small on the timescale of a half of century, this bomb radiocarbon acts as a pulse label for ecosystem studies of carbon turnover (Gaudinski et al., 2000). Therefore, the uptake of bomb radiocarbon can be used to measure microbial activity as it allows for us to infer timescales of carbon exchange between the atmosphere and a given reservoir on annual to decadal timescales (Ziolkowski et al., 2013).

The goal of this study was to assess the activity and community composition of the endolithic community inhabiting gypsum in the Canadian high Arctic. To achieve this goal, we combined techniques in isotope organic geochemistry, genetic sequencing, microscopy and spectroscopy. Combined with climate data, this work provides an overview of this polar microbial community and a new recognition of how environmental stresses such as prevailing polar desert conditions may affect the biogeochemical dynamics of high Arctic endolithic microorganisms. Furthermore, understanding carbon turnover as well as microbial community composition and function advances our knowledge of the ecology of these biomes, which will change as a function of recognized warming across this polar landscape. 


\section{Methods}

\subsection{Sampling site}

Gypsum Hill is an evaporitic diapir located along the Expedition River on western Axel Heiberg Island, Nunavut $\left(79^{\circ} 26^{\prime} \mathrm{N}, 90^{\circ} 46^{\prime} \mathrm{W}\right.$; Fig. 1). The evaporitic diapir is composed mostly of gypsum, hence the name Gypsum Hill, and to date most of the work at this site has focused on sulfurrich perennial springs (e.g., Pollard et al., 2009). The region is classified as polar desert with a mean annual temperature of $-15^{\circ} \mathrm{C}$ (Andersen et al., 2008) and a low rate of precipitation $\left(<65 \mathrm{~mm} \mathrm{yr}^{-1}\right)$, which mostly falls as snow (AES, 1984). In the field, rocks were assessed for endolithic colonization by visual confirmation of microbial pigments in fractured samples, which often form distinct horizons beneath the outer rock surface (Fig. 2). We studied the southwest face of the diapir, which was very friable. Rock samples of both the superficial crust and underlying gypsum down to a depth of $\sim 10 \mathrm{~cm}$ were aseptically collected in May and July 2010 from outcrops along the northeast slope of Gypsum Hill, stored in sterile plastic sampling bags or jars and subsequently frozen at $-20^{\circ} \mathrm{C}$ until processing for laboratory analyses.

\subsection{Field measurements}

In order to gain insight into how the environmental conditions impact endolithic colonization, micrometeorological measurements of air and rock temperatures as well as photosynthetically active radiation (PAR) were recorded during spring and summer field campaigns. Temperatures were measured on the rock surface and inside the endolithic habitat at approximate colonization depths using a 28-gauge copperconstantan thermocouple wire (Omega Engineering, Stamford, CT, USA) connected to a CR10X datalogger (Campbell Scientific, Logan, UT, USA) with $0.1{ }^{\circ} \mathrm{C}$ accuracy. Temperatures were recorded as either averaged $15 \mathrm{~min}$ periods for a total of $39.5 \mathrm{~h}$ (April 2012) or at $1 \mathrm{~s}$ intervals totaling $29 \mathrm{~h}$ (July 2011). Air temperature was simultaneously measured using a $107 \mathrm{~F}$ temperature probe (Campbell Scientific, Logan, UT, USA). Concurrently, PAR was measured using a LI190SB quantum sensor (Li-Cor Inc., Lincoln, NE, USA) with a spectral range between 400 and $700 \mathrm{~nm}$ and recorded as averaged photosynthetic photon flux density $\left(\mu \mathrm{mol} \mathrm{s}{ }^{-1} \mathrm{~m}^{-2}\right)$.

\subsection{Lipid extraction}

Microbial lipids were isolated and quantified to study the metabolic pathways and carbon cycling of the viable microbial community. Homogenized rock samples $(100 \mathrm{~g})$ were extracted twice using the modified Bligh and Dyer process (White et al., 1979). The organic phase was collected and both glycolipid fatty acid (GLFA) and phospholipid fatty acid (PLFA) fractions separated from the neutral lipids by sil-

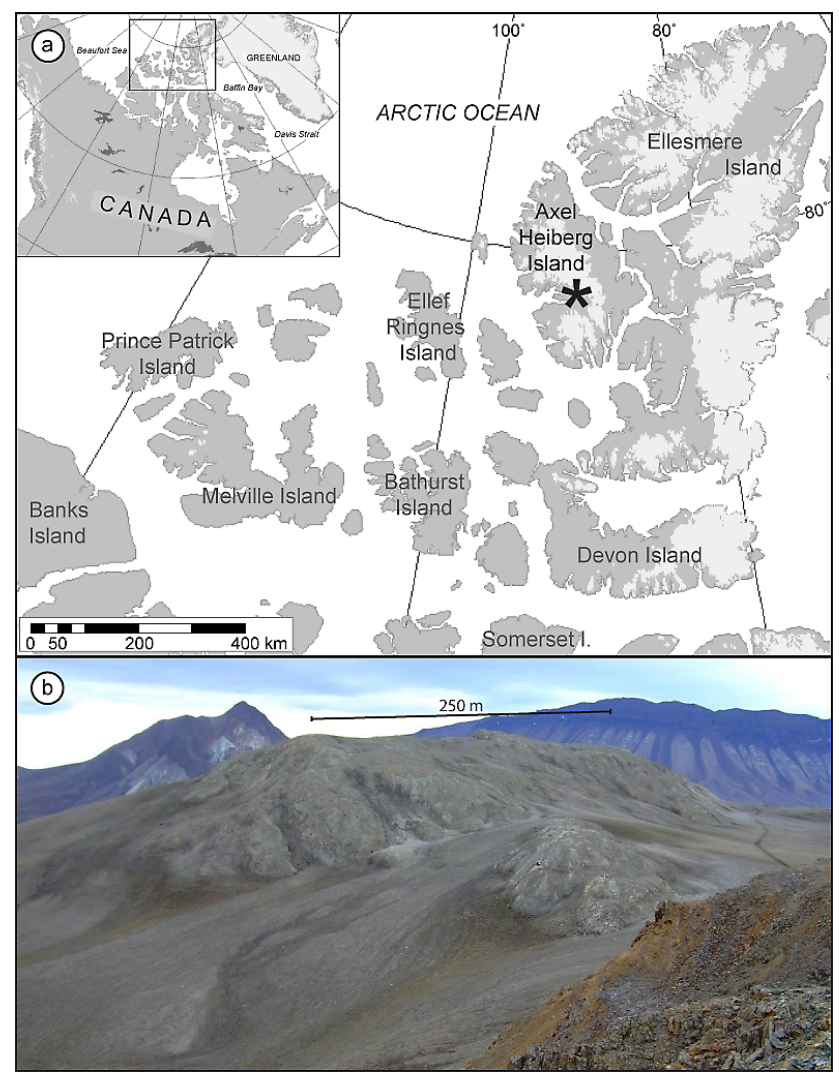

Fig. 1. (a) Study area map showing the location of Gypsum Hill diapir near the head of Expedition Fiord on western Axel Heiberg Island. (b) Photo of Gypsum Hill diapir.

ica gel chromatography. After separation, both the GLFA and PLFA fractions were evaporated to dryness under a stream of nitrogen gas and reacted to fatty acid methyl esters (FAME) via mild alkaline methanolysis (Guckert et al., 1985). FAME were further purified using a second silica gel and eluted with $5 \mathrm{~mL}$ of hexane, $5 \mathrm{~mL}$ of dicholomethane (FAME) and $5 \mathrm{~mL}$ of methanol.

Fatty acid methyl esters were separated, identified and quantified on an Agilent 6890 gas chromatograph coupled to an Agilent 5973 quadrupole mass spectrometer outfitted with a DB-5 MS column $(30 \mathrm{~m} \times 0.25 \mathrm{~mm}, 0.25 \mu \mathrm{m}$ film thickness). FAME were quantified using commercially available (Supelco Inc.) calibration standards methyl tetradecanoate, methyl hexadecanoate, methyl octadecanoate and methyl eicosanoate. FAME were identified using bacterial reference standards (Matreya bacterial acid methyl esters mix and Sigma 37 FAME mix), mass-fragmentation patterns and retention times.

\subsection{Isotopic $\left({ }^{13} \mathrm{C}\right.$ and $\left.{ }^{14} \mathrm{C}\right)$ analysis of FAME}

Stable carbon isotope ratios $\left(\delta^{13} \mathrm{C}\right)$ of individual FAME were determined using an Agilent 6890 GC coupled to a Thermo Delta Plus XP isotope mass spectrometer via a Conflo III 
interface. Reproducibility for isotopically characterized hexadecane and octacosane laboratory standards was better than $0.3 \%$. Precision for microbial FAMEs was typically $0.5 \%$ o minimum of three analyses, and all analyses were less than $1.5 \%$.

The ${ }^{14} \mathrm{C}$ content of FAME was determined on whole PLFA and GLFA extracts as described in Ziolkowski et al. (2013). Samples were transferred to prebaked $6 \mathrm{~mm}$ quartz tubes using $1 \mathrm{~mL}$ of dichloromethane and dried under UHP nitrogen. After $\mathrm{CuO}$ and silver wire were added, tubes were evacuated to $10^{-6}$ Torr and flame-sealed under vacuum. Tubes were then heated to $850^{\circ} \mathrm{C}$ for $2 \mathrm{~h}$. The resulting $\mathrm{CO}_{2}$ was purified, quantified and reduced to graphite using standard procedures (Santos et al., 2007). ${ }^{14} \mathrm{C}$ measurements were performed at KECK Carbon Cycle Accelerator Mass Spectrometry Laboratory at University of California Irvine. The reported data are in $\Delta^{14} \mathrm{C}$ notation expressed in \%o, which is the deviation of a sample from the $95 \%$ activity in 1950 AC of Natural Bureau of Standards (NBS) oxalic acid 1 normalized to $\delta^{13} \mathrm{C}=-25 \%$ with respect to Pee Dee Belemnite (Olsson, 1970; Stuiver and Polach, 1977). Both $\delta^{13} \mathrm{C}$ and $\Delta^{14} \mathrm{C}$ values were corrected during data processing for the addition of methanol carbon during derivatization. PLFA ${ }^{14} \mathrm{C}$ was measured in duplicate and GLFA ${ }^{14} \mathrm{C}$ was measured in triplicate.

The methyl ester derivatives of PLFA and GLFA are designated in terms of the total number of carbon atoms : number of double bonds, followed by the position of the double bond from the methyl end of the molecule. The prefixes $a$ and $i$ indicate anteiso and iso branching, br indicates an unknown methyl branching position.

\subsection{Community profiling}

We characterized the community profile of the endolithic communities to study the diversity of the microbial population. All processing of samples and nucleic acids was conducted in UV-sterilized biosafety cabinets. Total community genomic DNA was extracted aseptically from several grams (ranging between 1 and $10 \mathrm{~g}$ ) of the most populated (darkest green area) gypsum samples using the MoBio UltraClean Soil DNA Isolation Kit (MoBio, Carlsbad, CA, USA). Total DNA was pooled from multiple extractions to a final concentration of at least $300 \mathrm{ng}$ of gDNA. Pooling of samples from multiple samples was aimed at standardizing any extraction bias that might result from sample heterogeneity. Samples were sent for SSU gene pyrosequencing analyses at the Research and Testing Laboratory (RTL Lubbock, TX, USA) using the Roche 454 GS-FLX platform (Roche 454, Branford, CT, USA). A total of four sample libraries were prepared with the following primers for bacterial 16S rRNA (28F-5'-GAGTTTGATCNTGGCTCAG-3', 519R-5'-GTNTTACNGCGGCKGCTG-3'), archaeal $16 \mathrm{~S}$ rRNA (F-5'-GYGCASCAGKCGMGAAW-3', R5'-GGACTACVSGGGTATCTAAT-3'), eukaryal/fungal 18S rRNA (ISSU) (F-5'-TGGAGGGCAAGTCTGGTG-3',
R-5'-TCGGCATAGTTTATGGTTAAG-3'), and chloroplast 23S rRNA (5'-GGACAGAAAGACCCTATGAA-3', R-5'TCAGCCTGTTATCCCTAGAG-3') genes. The $23 \mathrm{~S}$ primers flank domain $\mathrm{V}$ of the $23 \mathrm{~S}$ plastid rRNA gene, which is present in all photosynthetic microorganisms (Sherwood and Presting, 2007) including cyanobacterial and eukaryotic algae. Sequencing was performed using titanium amplicon pyrosequencing (bTEFAP) using a one-step PCR as previously described (Dowd et al., 2008a). Pyrotagged samples were amplified using ePCR using Hot Start and HotStar high-fidelity $T a q$ (Qiagen) to generate $\sim 400 \mathrm{bp}$ reads for each of the above primer libraries at a sequence depth of 3000 reads per sample. All instances of sequencing and quality filtering were conducted by the RTL sequencing facility and included removing primer sequences, reads $<200 \mathrm{bp}$ long, sequences with ambiguous base calls, homopolymer repeats greater than $6 \mathrm{bp}$ and chimera removal (Dowd et al., 2008a, b).

Filtered quality sequences were aligned using the Ribosomal Database Project Pyrosequencing Pipeline (Michigan State University, http://pyro.cme.msu.edu/index.jsp) for the bacterial and archaeal 16S libraries, and using the Silva SSU and LSU reference alignments (Pruesse et al., 2012) for the fungal $18 \mathrm{~S}$ and algal $23 \mathrm{~S}$, respectively. Operational taxonomic units (OTUs) were assigned using complete linkage clustering at $97 \%$ similarity (Cole et al., 2009). OTUs were taxonomically classified using BLASTn against the NCBI non-redundant nucleotide database (Altschul et al., 1990), and the Silva database (Release 108) and verified using the RDP classifier (Wang et al., 2007). Diversity was estimated using the Shannon and Chao indices and were calculated using the RDP and Qiime pipelines (Caporaso et al., 2010), and a $97 \%$ cut-off. OTUs accounting for greater than $1 \%$ of the total reads in each data set were used in generating community taxonomic profiles (Supplement Table 1). The representative sequences for the $>1 \%$ OTUs for each data set were trimmed to the shortest sequence length, aligned using ClustalW with ambiguously aligned positions removed, and the alignments used to generate maximum likelihood and neighbor-joining phylogenetic trees using the MEGA 5.0 package (Tamura et al., 2011). Sequence data sets were submitted to the NCBI Sequence Read Archive under accession number SRA074427.

\subsection{Culturing and microscopy}

To determine the viability of the microbial community, subsamples $(\sim 1 \mathrm{~g})$ of gypsum were taken for culturing using BG-11 $+\mathrm{N}$ in both liquid and solid (1.5\% agar) media and incubated at room temperature under full spectrum light with a $16: 8$ light : dark cycle for three months. Growth was determined by turbidity in liquid culture and colonies on solid media, which were viewed under bright field, phase-contrast and fluorescence conditions using a BX41 microscope (Olympus America Inc., Center Valley, PA, USA) equipped with 
a U-DM-CY3 wide bandpass fluorescence filter cube (green excitation, $565 \mathrm{~nm}$ cut-on wavelength).

In order to characterize the fine details of the physical and chemical properties of the endolithic colonies within the gypsum, we employed scanning electron microscopy (SEM). Rocks were fractured in cross section to expose interiors that included the region encompassing endolithic microorganisms. A first set of samples was fixed in aqueous glutaraldehyde ( $2 \% v / v$ final concentration) for $1 \mathrm{~h}$ followed by dehydration in a graded ethanol series (50, 70, 90, 95 and $100 \%$ ) and critical-point dried before coating with $10 \mathrm{~nm}$ osmium. Samples were imaged on a LEO (Zeiss) 1540XB field emission gun SEM (Carl Zeiss, LLC, Peabody, MA, USA) equipped with a secondary electron secondary electron (SE) detector at an operating accelerating voltage of 5$10 \mathrm{keV}$ and $5 \mathrm{~mm}$ working distance. To assess variations in chemical composition, a second set of samples was prepared by chemical fixation and dehydration followed by embedding in LR White acrylic resin (London Resin Company Inc., London, England) in 1" diameter molds. These were subsequently ground and polished to expose the endolithic interior, coated with $10 \mathrm{~nm}$ osmium and imaged on the 1540XB SEM using a quadrant back scattering detector (QBSD) with signal intensity related to atomic number.

The presence and distribution of trace metals were assessed on uncoated polished samples by synchrotron radiation-based micro-X-ray fluorescence $(\mu-X R F)$ spectroscopy on the VESPERS beamline at the Canadian Light Source (University of Saskatchewan, Saskatoon, SK, Canada). Incident X-rays of $13.5 \mathrm{keV}$ energy were chosen to excite elements up to $\mathrm{Pb}$. $\mu$-XRF data were captured at a $10 \mu \mathrm{m} \times 10 \mu \mathrm{m}$ spot size using a single-element Si detector, with spectral analysis of the fluorescence spectrum of each pixel providing spatial images for each element analyzed. Images were analyzed and evaluated for co-located elements using Sam's Microprobe Analysis Kit (Webb, 2012).

\section{Results}

\subsection{Endolithic habitat and microclimatic conditions}

Generally, surficial rocks of Gypsum Hill appear dark brown in color and highly weathered (Fig. 2a). The endolithic communities were identified by lateral pigmentation extending along horizons 1 to $5 \mathrm{~mm}$ beneath the surface. Shallower bands were distinctly green and brown in color, with more diffuse pink pigmentation extending deeper into the rock (Fig. 2). Given the heavily weathered nature of the gypsum, these horizons are generally discontinuous; however, a larger survey of the diapir showed that endolithic microbial colonization is widespread.

To assess the environmental conditions of the endolithic habitat, the environmental conditions on the surface and within the gypsum were measured. During the spring data
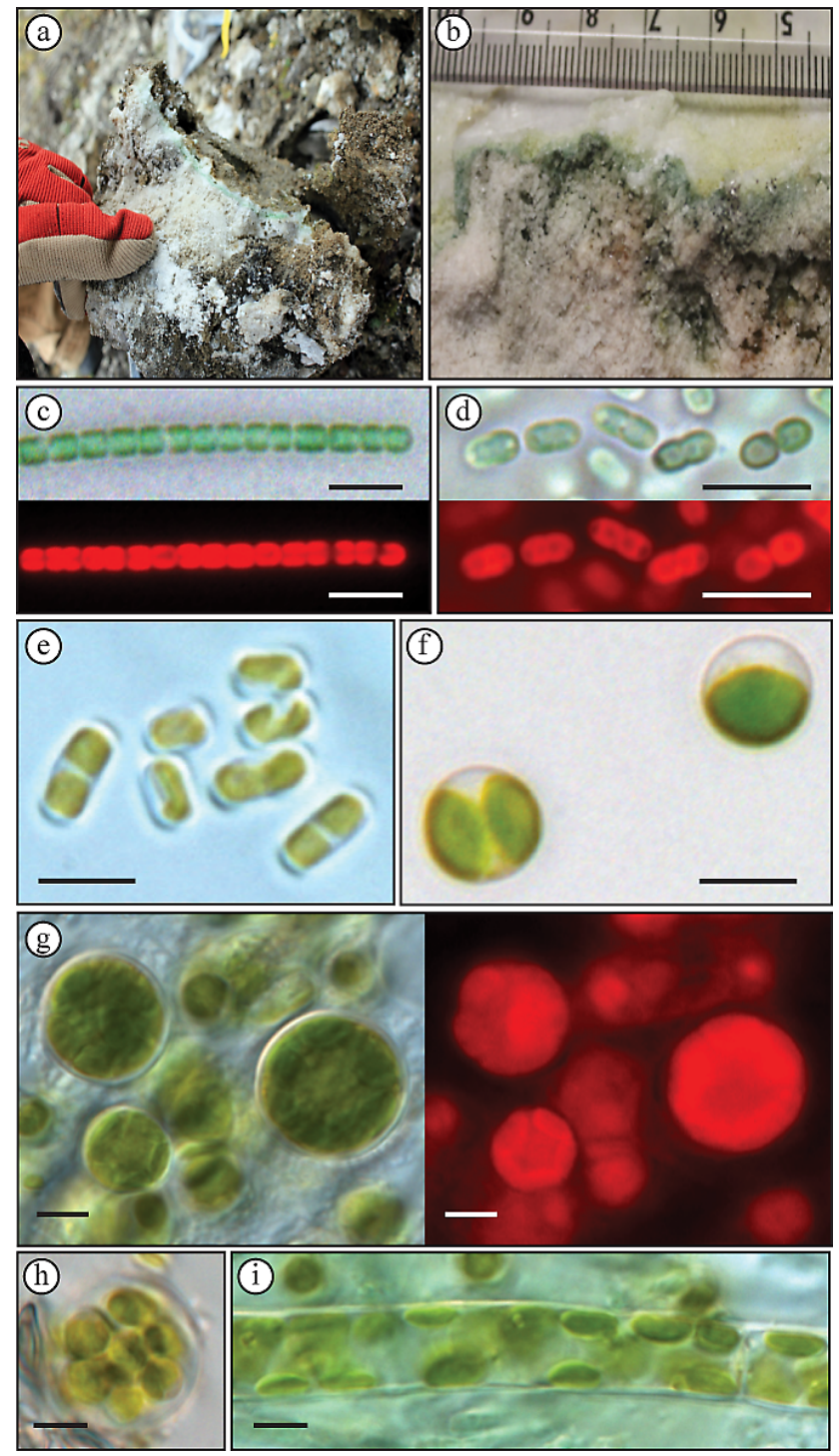

Fig. 2. (a) Field sample of gypsum containing endolithic microorganisms. Note green banding beneath surface crust (b). Both filamentous and coccoid cyanobacteria $(\mathbf{c}, \mathbf{d})$ and algae $(\mathbf{e}-\mathbf{i})$ were cultured from collected samples, with photosynthetic pigment autofluorescence showing cell viability.

collection period, the average air temperature was $-16.6{ }^{\circ} \mathrm{C}$ (Fig. 3a), a few degrees warmer than the yearly average temperature (Pollard et al., 2009). In contrast, rock surface and subsurface temperatures were much warmer than the overlying air as they were heated to near or above $0{ }^{\circ} \mathrm{C}$ (Fig. 3a). Maximum temperature differences between the overlying air and the endolithic habitat ranged from $13.2^{\circ} \mathrm{C}$ for the rock surface to $10.9^{\circ} \mathrm{C}$ in the colonized region and occurred during times of highest PAR (maximum $640 \mu \mathrm{mol} \mathrm{s}^{-1} \mathrm{~m}^{-2}$ ). During the summer collection period, although rock temperatures were much higher due to warmer air temperatures and $24 \mathrm{~h}$ incoming solar radiation, the differences between the 

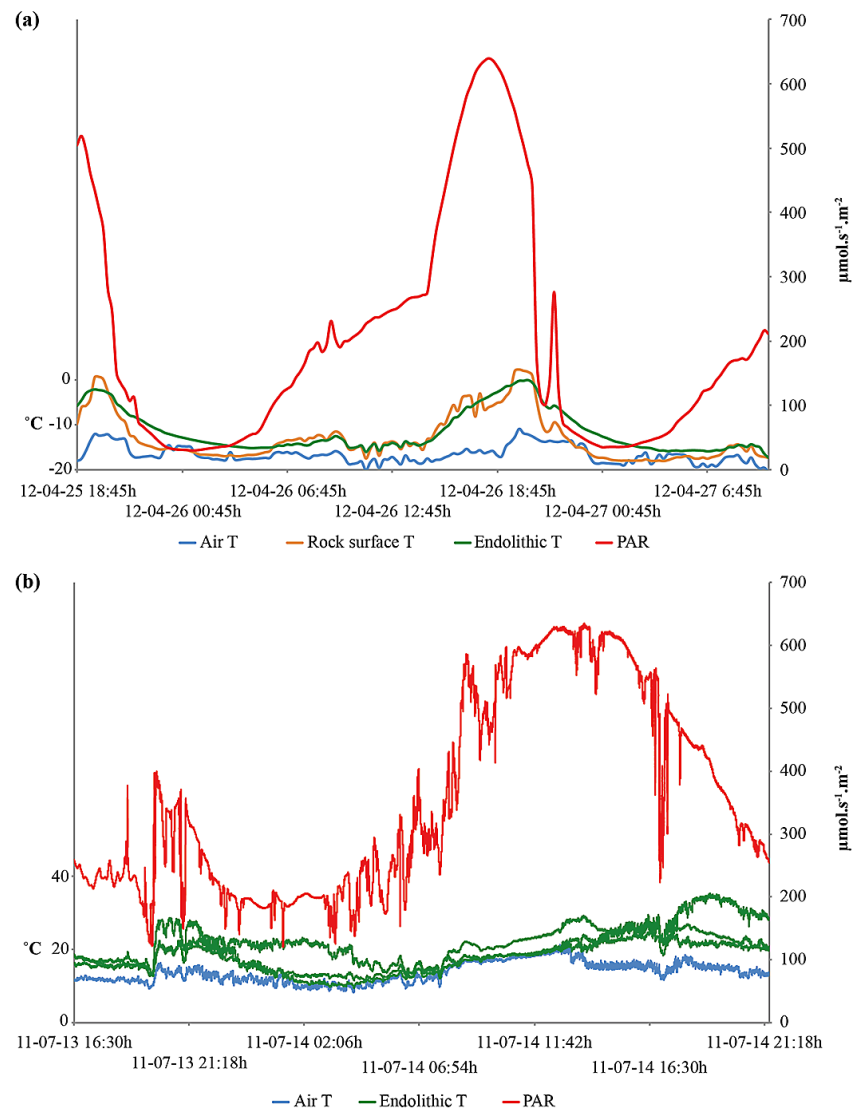

Fig. 3. Microclimate data collected at the field site, including air temperature, rock surface temperature, endolithic temperature and photosynthetically active radiation (PAR). (a) 15 min averaged data collected in April 2012. Both rock surface and subsurface temperatures are higher than air temperature due to solar radiation that heats rock surfaces. (b) $1 \mathrm{~s}$ data collected in July 2011. Temperature fluctuations result from variability in PAR; however rock temperatures are always higher than air temperature. Variations in endolithic temperatures due to data collected from outcrops with different aspects.

air temperature and endolithic habitat were smaller (Fig. 3b). Subsurface colonized regions were on average $5.7^{\circ} \mathrm{C}$ warmer than average air temperatures $\left(13.8^{\circ} \mathrm{C}\right)$ during the summer, with a maximum temperature difference of $13.5^{\circ} \mathrm{C}$ over air temperature. The maximum PAR measured during this study was lower than previous measurements of PAR on nearby Ellesmere Island (Omelon et al., 2006a; Lafleur et al., 2012) due to measurement times outside the highest sun angle, but was still significantly higher than the minimum PAR required $\left(100 \mu \mathrm{mol} \mathrm{s}^{-1} \mathrm{~m}^{-2}\right)$ for endolithic growth (Johnston and Vestal, 1993).

\subsection{Community composition}

Laboratory incubation of subsamples showed abundant growth of viable cyanobacteria and algae (Fig. 2). Pyrosequencing of the $16 \mathrm{~S}, 18 \mathrm{~S}$ and $23 \mathrm{~S}$ plastid rRNA genes of the bacterial/archaeal, fungal and chloroplast components, respectively, were used to profile the microbial community; a summary of the most abundant taxa ( $>1 \%$ of total filtered sequence reads) is presented in Fig. 4 and sequencing statistics describing the individual data sets are included in Supplement Table S1

The phototrophic bacterial community was dominated by cyanobacteria ( $21 \%$ of total bacterial reads; related to Nostoc sp., Loriellopsis sp., Chroococcidiopsis sp.) with many of the closest matching sequences originating from endolithic habitats from Antarctica or other dry desert hypolith and soils (Fig. 5). The bacterial community (with a total of 4340 filtered reads) also contained a large proportion of microbial heterotrophs dominated by $\alpha$-Proteobacteria (35\% of total reads; related to unclassified Rhizobiales, Rubellimicrobium sp., Caulobacter sp., Sphingomonas sp.), $\beta$-Proteobacteria (21\% of total reads; related to Delftia sp., Rubrivivax sp.), and Actinobacteria (16\% of total reads; related to Rubrobacter sp., Patulibacter sp.). The best matches for heterotrophic sequences were also primarily from other polar/cold, desert, endolithic habitats. With one exception, the $\beta$-Proteobacteria-related sequences were closely matched to clones from hydrocarbon contaminated soils or anaerobic biofilm/rhizosphere communities (Fig. 5).

The rocks were colonized by a surficial lichen community; however, fungal sequences (1845 total filtered reads) were also recovered from the endolithic region that contained a diversity of fungal species with an abundance of lichenizing Ascomycota (35\% endolithic Verrucariales) (Supplement Fig. 1). The closest sequences from the fungal assay (18S SSU) matching the endolithic fungi were isolates from Verrucaria sp., Thalidium sp., and Bagliettoa sp. isolated from mineral biofilms or other lithic substrates. One of the sequences was closely matched to a Phoma sp. isolated from the Antarctic. The community also contained less diverse algal and archaeal components with assays for green algae (23S rRNA plastid) and archaeal 16S rRNA yielding very few $(<250)$ corresponding reads. The few green algal sequences were closely matched with Trebouxia sp. and Trichosarcina sp., known lichenizing symbionts, with the remainder of the sequences predominantly matching cyanobacteria Chroococcidiopsis sp., Nostoc sp. and Cyanothece sp. (Supplement Fig. 2). The few archaeal sequences were closely matched to Thaumarchaeota ( $97 \%$ of archaealspecific reads, data not shown) dominated by sequences most closely matching Nitrososphaera sp. The overall community indices demonstrated a high level of diversity among the bacterial (Chao $\left.=716, H^{\prime}=5.64\right)$ and the fungal communities (Chao $=68, H^{\prime}=1.99$ ), while the less abundant community members had much lower diversity among the green algae $\left(\mathrm{Chao}=6, H^{\prime}=0.7\right)$ and archaea $\left(\right.$ Chao $\left.=8, H^{\prime}=0.9\right)$. 


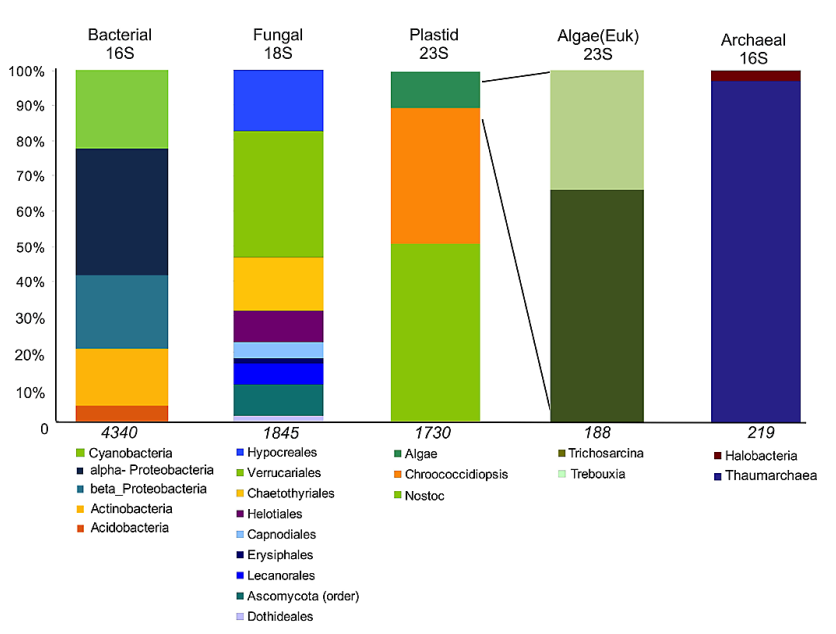

Fig. 4. Cryptoendolithic community profile based on SSU and LSU pyrotag sequence analyses. Only sequences $>1 \%$ of the total reads were used to construct the percent composition of OTUs for each group, and the total numbers of filtered reads per data set is shown (italics). The data are presented at different taxonomic resolution; primarily at phylum level with the green algal subgroup shown to the genus level.

\subsection{Microbial lipids: abundance and isotopic composition $\left({ }^{13} \mathrm{C},{ }^{14} \mathrm{C}\right)$}

To assess the diversity and rate of carbon turnover of viable microbial community, we measured the abundance and isotopic composition of the microbial membranes. Within the endolithic habitat, PLFA were both concentrated and highly variable $\left(6.2 \times 10^{4} \mathrm{pmol} \mathrm{g}^{-1} \pm 100 \%, n=3\right)$; this variability is likely due to observed patchy colonization. If the PLFA concentrations are converted to an estimate of cellular abundance, using a generic conversion factor of $2 \times 10^{4}$ cells pmol $^{-1}$ (i.e., Green and Scow, 2000), we calculate a cellular density of $2 \times 10^{10}$ cells $\mathrm{g}^{-1}$ rock. While endolithic colonization typically develops as thin laminae beneath the rock surface, our estimate of cellular density includes some uncolonized rock due to large sample requirements for isotope analysis. Therefore, the cell abundance is estimated to be higher than $10^{10}$ cells $^{-1}$ in the regions of highest colonization, which is two orders of magnitude higher than the cellular densities of endolithic communities in gypsum in the Atacama Desert (Ziolkowski et al., 2013) and nearby polygon soils (Steven et al., 2008). Since the cellular abundance in endolithic systems can be impacted by how much non-colonized rock was included in the sample, caution should be taken when comparing the cell abundance in different systems.

The distribution of the PLFA also suggested that there was a diverse community (Table 1). There were many short-chain PLFA, ubiquitous in bacterial communities, and polyunsaturated PLFA (18:2 and $18: 3)$, commonly found in algae, cyanobacteria and fungi (Table 1). Our PLFA data agree with
Table 1. Phospholipid and glycolipid fatty acid distribution and stable carbon isotopic composition. The bulk organic carbon composition of the gypsum had a stable carbon isotopic value of $-27.2 \%$. Uncertainty of $\delta^{13} \mathrm{C}$ measurements was less than $\pm 1.5 \%$.

\begin{tabular}{|c|c|c|c|c|}
\hline & \multicolumn{2}{|c|}{ FAME distribution } & \multicolumn{2}{|c|}{$\delta^{13} \mathrm{C}$} \\
\hline & $\begin{array}{l}\text { PLFA } \\
\text { mol \% }\end{array}$ & $\begin{array}{l}\text { GLFA } \\
\text { mol \% }\end{array}$ & $\begin{array}{r}\text { PLFA } \\
\% \circ\end{array}$ & $\begin{array}{r}\text { GLFA } \\
\% \circ\end{array}$ \\
\hline $14: 0$ & - & 1.7 & & \\
\hline$i 14: 0$ & 4.4 & 1.0 & & \\
\hline$a 14: 0$ & 2.5 & 0.6 & & \\
\hline$i 15: 0$ & 4.5 & 2.5 & -29.2 & -31.8 \\
\hline $16: 0$ & 12.0 & 9.2 & -35.0 & -35.1 \\
\hline br16: 0 & 2.8 & 3.8 & & \\
\hline $16: 1$ & 14.4 & 7.9 & -33.2 & -36.9 \\
\hline br17 : 0 & - & 0.3 & & \\
\hline br16: 1 & 4.0 & - & & \\
\hline$i 17: 0$ & - & 0.3 & & \\
\hline $16: 2$ & - & 0.8 & & \\
\hline $17: 1$ & 9.8 & 2.6 & -36.9 & -37.6 \\
\hline $18: 0$ & - & 1.2 & & \\
\hline $16: 3$ & - & 0.9 & & \\
\hline $18: 1$ & 16.9 & 15.7 & & -36.4 \\
\hline $18: 1$ & 10.3 & 3.9 & -33.8 & \\
\hline $18: 2$ & 11.7 & 29.8 & -37.0 & -38.2 \\
\hline $18: 3$ & 6.7 & 14.8 & -40.1 & \\
\hline $20: 2$ & - & 0.5 & & \\
\hline $20: 4$ & - & 1.3 & & -41.0 \\
\hline $20: 5$ & - & 1.5 & & -27.8 \\
\hline saturated & 12 & 13 & -35 & -35 \\
\hline mono & 51 & 33 & -34 & -36 \\
\hline poly & 19 & 49 & -39 & -38 \\
\hline \multirow[t]{2}{*}{ branched } & 18 & 5 & -33 & -35 \\
\hline & & $\begin{array}{r}\Delta^{14} \mathrm{C} \\
(\% \circ)\end{array}$ & $\begin{array}{r}+106 \pm 10 \\
n=2\end{array}$ & $\begin{array}{r}+78 \pm 26 \\
n=3\end{array}$ \\
\hline
\end{tabular}

the diversity of the endolithic community observed in the molecular data and the presence of both primary producers (cyanobacteria, algae and lichen) and decomposers (heterotrophic bacteria, fungi) (Walker and Pace 2007). The distribution of GLFA was distinct from the PLFA, with almost half of the observed GLFA being unsaturated FAME with a chain length of 18 carbons, $18: 2$ being the most abundant GLFA (Table 1).

The stable carbon isotope data provide information about the carbon assimilation within the endolithic habitat. Organic carbon, assumed to be an admixture of the viable microbial community and dead organic material, had a $\delta^{13} \mathrm{C}$ signature of $-27.2 \%$. The $\delta^{13} \mathrm{C}$ of the PLFA and GLFA were 8 and $10 \%$ more depleted than the total organic carbon (Table 1), which is consistent with the relatively large discriminations between bulk cells and PLFA expected for autotrophic communities (Hayes, 2001). Even though the average $\delta^{13} \mathrm{C}$ values of the PLFA and GLFA were within 

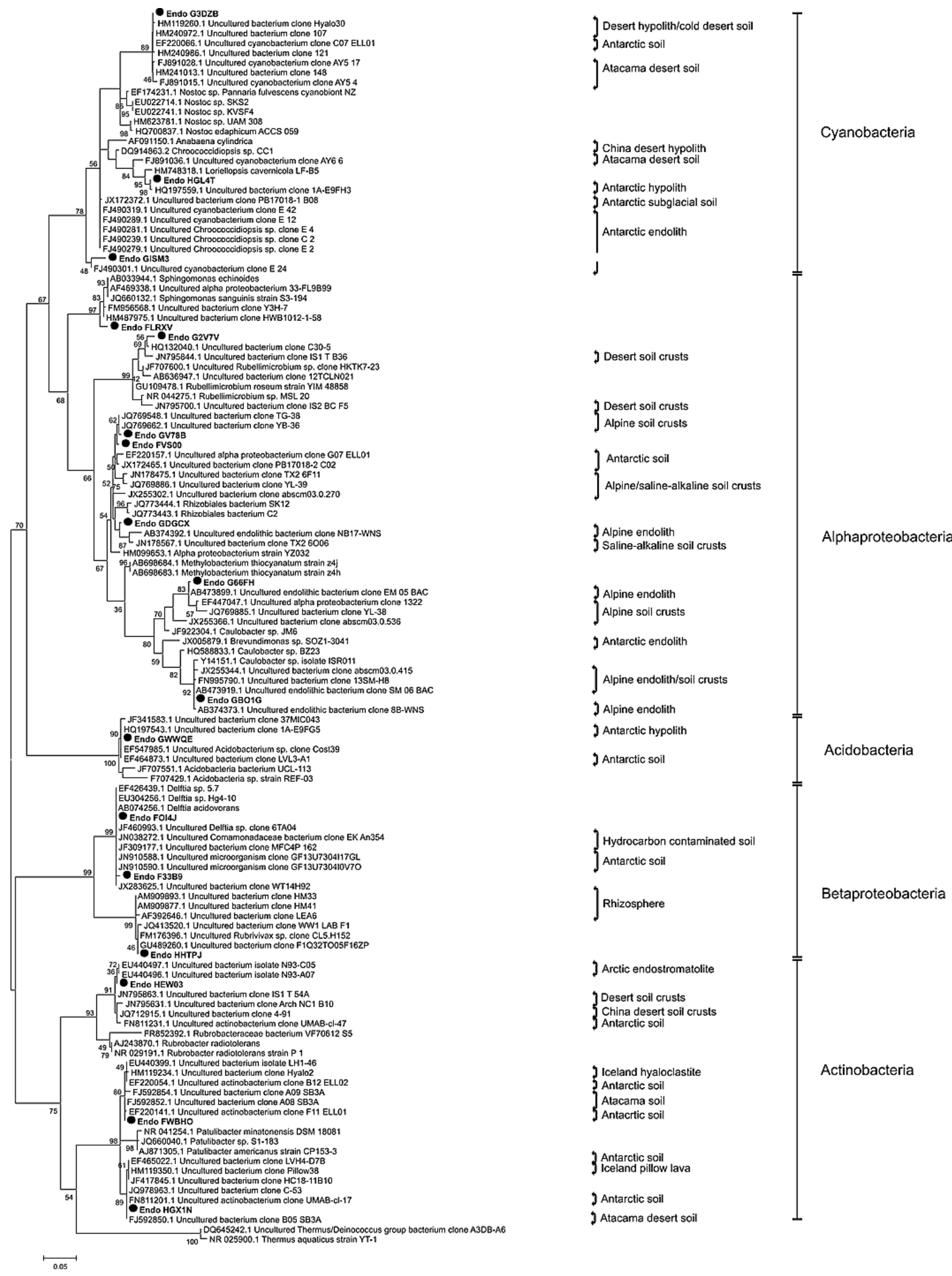

Fig. 5. Maximum likelihood (ML) phylogenetic tree illustrating the inferred relationship between $16 \mathrm{~S}$ rRNA gene sequences (527 bp) showing the position of dominant bacterial members of the endolithic community ( $\bullet$ bold) related to the most similar GenBank sequences. Taxa isolated from other extreme and/or endolithic environments are described. Bootstrap values (expressed as percentages of 500 replications) are shown at branch nodes. Similar topologies were recovered in trees generated with the neighbor-joining algorithm. Bar: 0.05 substitutions per nucleotide position. 
analytical uncertainty of each other, there were significant differences in the $\delta^{13} \mathrm{C}$ of individual PLFA and GLFA. Ubiquitous PLFA markers such as 16:0 and 18:1 had similar $\delta^{13} \mathrm{C}$ values $(-33 \pm 1 \%$ ), with the exception of $i 15: 0$, which was less depleted $\left(\delta^{13} \mathrm{C}=-29.2 \pm 1 \%\right.$ ). The GLFA most enriched in ${ }^{13} \mathrm{C}$ were $20: 5$ and $i 15: 0$ at -28 and $-32 \%$, respectively. The $\delta^{13} \mathrm{C}$ of polyunsaturated PLFA 18:2 and $18: 3(-37.0$ and $-40.1 \%$ respectively) and GLFA $20: 4$ $\left(-41.0 \%\right.$ ) were the most depleted in ${ }^{13} \mathrm{C}$.

Radiocarbon measurements of the microbial lipids provide an estimate of when the carbon within the viable cellular membranes was last in equilibrium with atmospheric $\mathrm{CO}_{2}$. Both PLFA and GLFA (Table 1) had positive $\Delta^{14} \mathrm{C}$ values $(+106 \pm 20 \%$ and $+78 \pm 20 \%$, respectively) that were more enriched in ${ }^{14} \mathrm{C}$ than present-day atmospheric ${ }^{14} \mathrm{C} \mathrm{CO}_{2}$ values (Czimczik and Welker, 2010). In the absence of an isotopic label, the only way that the microbes could contain the observed elevated amount of ${ }^{14} \mathrm{C}$ is through the incorporation of ${ }^{14} \mathrm{C}$ initially introduced to the atmosphere through nuclear weapons testing $50 \mathrm{yr}$ ago (Nydal and Lövseth, 1983). These elevated $\Delta^{14} \mathrm{C}$ values imply that the organisms are incorporating carbon that was recently in the atmosphere.

\subsection{Biogenic and physical weathering}

We also examined the extent of microbe-mineral interactions and physical weathering using microscopy and spectroscopy. SEM micrographs of the host rock reveals an irregular outer surface composed of weathered gypsum rind overlain by allochthonous debris (Fig. 6a, b). Weathering and absorption of water at Earth's surface conditions are likely responsible for transforming the primary anhydrite to gypsum, with mechanical freeze-thaw weathering leading to separation of gypsum crystalline sheets to create significant porosity and increased surface area (Fig. 6c) both at and beneath the rock surface. Freshly fractured samples show these endolithic habitats covered by bacteria and associated extracellular polymeric substances (EPS) (Fig. 6d, e). Relatively unweathered minerals dominate deeper within the rock, with microorganisms and EPS coating gypsum surfaces (Fig. 6f). It is possible that the endolithic colonization is limited to closer to the surface due to greater porosity closer to the surface, which may maximize the presence of water, light and space for microorganisms to grow (Fig. 6g). Examination of the interfacial contact between microorganisms and the underlying mineral substrate shows little evidence for dissolution or alteration of the inorganic surface, suggesting minimal microbe-mineral interaction (Fig. 6h).

Examination of polished blocks based on SEM-QBSD image analysis shows the endolithic habitat to be dominated by gypsum with an absence of other minerals (Fig. 7a). Closer inspection of a profile from the exposed surface down through the colonized region by $\mu$-XRF spectroscopy (Fig. 7b, c) shows the presence of trace metals that are homogeneously distributed within the endolithic habitat.
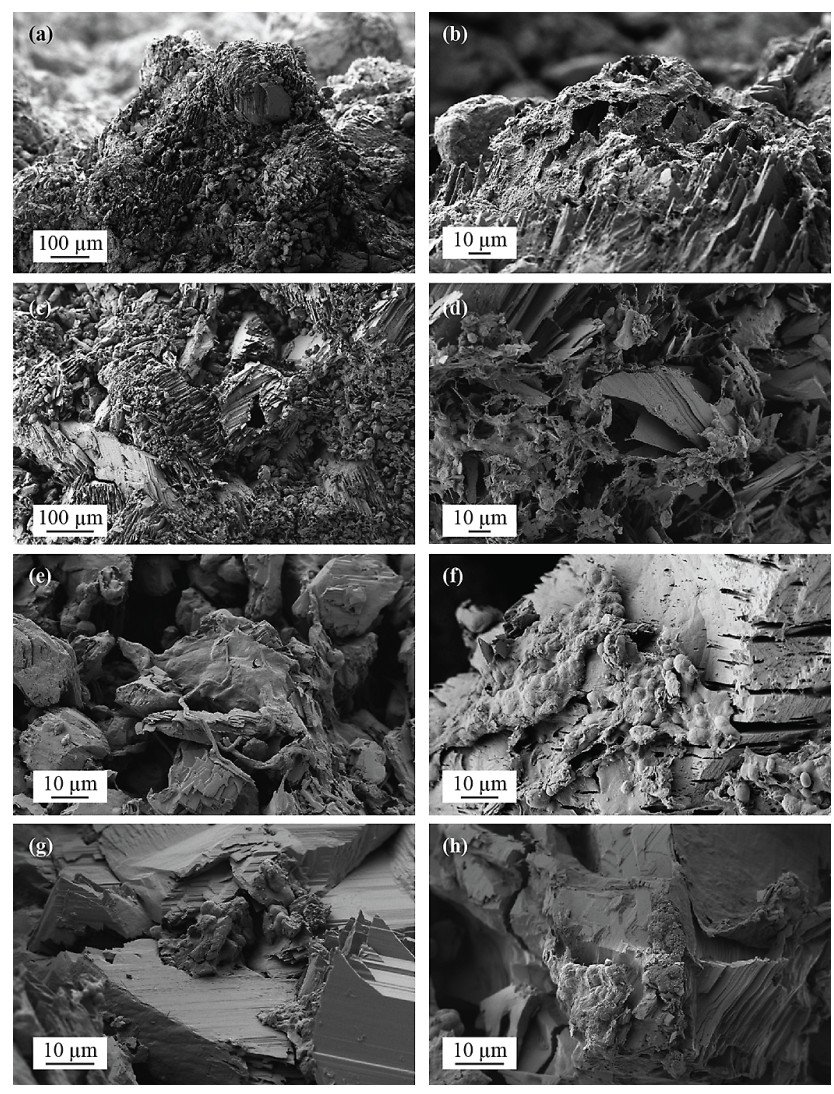

Fig. 6. SEM micrographs of the Gypsum Hill endolithic habitat. (a) Gypsum $\left(\mathrm{CaSO}_{4} \cdot 2 \mathrm{H}_{2} \mathrm{O}\right)$ forms from hydration of anhydrite $\left(\mathrm{CaSO}_{4}\right)$, with exposed minerals having irregular, jagged topography that is often coated in allochthonous debris (b) that forms a surface crust. (c) Freeze-thaw action results in cleavage along crystal planes, increasing porosity and available surface area. (d) Gypsum affected by freeze-thaw weathering showing abundant colonization by endolithic microorganisms and associated EPS. (e, f) Subsurface gypsum colonized by both filamentous and coccoid microorganisms and EPS. Note early stages of mineral weathering in (f). (g) Microbial colonization of small pore space within the endolithic habitat. (h) Examination of the microbe-mineral contact shows original mineral structure, suggesting that microbial activity does not enhance chemical weathering.

Two metals, Fe and Co, showed a weak correlation deeper than regions heavily colonized by endolithic microorganisms (Fig. 7d), which is consistent with the accumulation of iron below the depth of lichen colonization in Antarctic endolithic habitats (Johnston and Vestal, 1993).

\section{Discussion}

While extreme conditions of polar regions have long been thought to limit microbial diversity and activity within endolithic communities, we present data of a polar microbial community that is diverse and actively cycling with little evidence of microbe-mineral interaction. Molecular data 


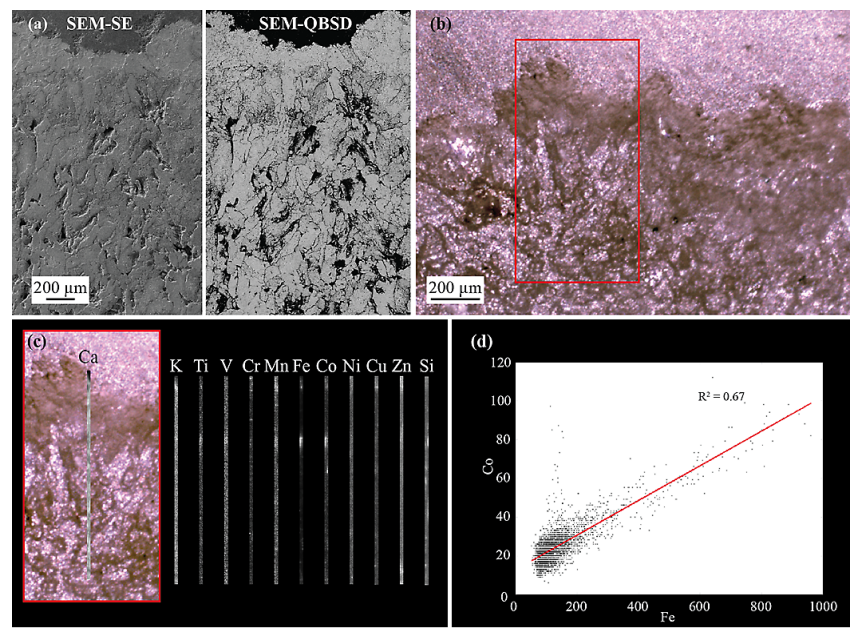

Fig. 7. (a) Cross-sectional micrographs of the outer surface and endolithic habitat under SEM-SE and SEM-BSE conditions. (a) Large void spaces exist beneath the surface crust, providing habitats for microbial colonization. Little contrast variability imaged by SEMBSE suggests the entire habitat to be composed of gypsum. (b) Light micrograph showing weathered outer surface (dark-colored areas) and subsurface habitat. Boxed area highlighted in (c), with $\mu-$ XRF transect from exposed surface down into the endolithic habitat. While calcium dominates, metals are heterogeneously distributed throughout the microenvironment. (d) Co-location analysis shows only a weak relationship between $\mathrm{Co}$ and $\mathrm{Fe}$, which are likely derived from allochthonous debris. Lack of a spatial correlation between metals and microorganisms suggests that bacteria are not involved in chemical weathering of the endolithic habitat.

provided information about the microbial community composition, the isotopic composition of the microbial lipids was used to assess the microbial activity, and spectroscopy was used to investigate the microbe-mineral interactions. Below we discuss these results in further detail.

\subsection{Microbial community composition}

Both the molecular data and distribution of microbial lipids indicate that the microbial community was dominated by cyanobacterial phototrophs along with a high diversity of active bacterial and fungal heterotrophic community members. Molecular data characterized all of the microbial communities present, whether they were dormant or active, while microbial lipids provided an integrated view of the viable microbial community. While many organisms make specific PLFA, many organisms also produce the same PLFA, which limit the ability of PLFA data to infer the activity of specific species or groups of organisms. However, natural abundance carbon stable isotope signatures of the microbial lipids provide insight into the various energy pathways present. Of the viable microbial community, the wide variation of stable carbon isotope values for individual PLFA clearly illustrate that a number of diverse organisms are present. Autotrophic or- ganisms typically exhibit smaller $\delta^{13} \mathrm{C}$ offsets between atmospheric $\mathrm{CO}_{2}$ and microbial lipids than heterotrophic organisms (Hayes, 2001). In this system, while the $\delta^{13} \mathrm{C}$ of many PLFA were consistent with autotrophy, a number of lipids (e.g., PLFA $18: 2$ and $18: 3$, GLFA $18: 2$ and $20: 4$ ) were significantly more depleted in ${ }^{13} \mathrm{C}$, which is consistent with heterotrophy (Hayes, 2001). Thus, of the viable microbial community, a wide diversity of metabolic/energy pathways were observed. This in turn supports that much of the diversity observed in the phylogenetic analyses both heterotrophs and phototrophs were active within the endolithic community.

The majority of the endolithic bacterial community detected using molecular techniques was most closely matched to isolates or clones from cold/dry deserts (i.e., Antarctica, Atacama, cold alpine environments). Thus, the microbial community profile is consistent with communities of known extreme environments, suggesting most microbial members are adapted and suited to be inhabiting the cold and dry Arctic endolithic habitat. However, the relative diversity of the community is greater than those described from the harsher endolithic habitats of the McMurdo Dry Valleys of Antarctica $\left(H^{\prime}=2.3\right.$ to 3.3, Pointing et al., 2009), the Atacama $\left(H^{\prime}=2.7\right.$ to 4.1 Lacap et al., 2011) and high-altitude Tibetan deserts $\left(H^{\prime}<0.9\right.$, Wong et al., 2009). Overall, this higher level of diversity is interpreted to suggest that the Arctic gypsum is not as extreme of a habitat, likely due in part to the more moderate temperatures and higher precipitation present than in either the Atacama Desert or Antarctica, and that the conditions are able to support the activity of less extremophilic species known to inhabit endolithic environments found in places such as mid-latitude alpine and temperate lithic habitats (Walker and Pace, 2007a; Horath and Backofen, 2009). It is worth noting that the depth of community sampling in previous studies is limited to clonebased molecular characterization, which supports the current consensus that endolithic habitats are simple systems with restricted diversity (Walker and Pace, 2007b). The higher bacterial diversity captured within this community may be driven in part by the use of deep sequencing that captures more of the microbial community diversity as observed in many environmental systems. Nonetheless, this community profile is characteristic of specialized endolithic- and lichenassociated communities inhabiting lithic surfaces distinct from the microbial communities from the surrounding tundra and permafrost that host greater diversity (data not shown).

The description of endolithic communities often makes the distinction between lichen- vs. cyanobacteria-dominated communities (de la Torre et al., 2003). In this community both communities are present within the endolithic habitat although the cyanobacteria are the more dominant primary producers (Chroococcidiopsis sp. and filamentous Nostoc sp.) versus the algal lichen photobionts (Trebouxia sp.). The phototrophic community in particular was dominated by only a few species, primarily Chroococcidiopsis sp., a highly 
desiccation-resistant cyanobacterium, and a dominant photosynthetic organism in extreme endolithic habitats (Friedmann and Ocampo-Friedmann, 1995; Bahl et al., 2011). Other common endolithic taxa that were not found in abundance include the low-light-tolerant cyanobacterium Gloeocapsa sp. (de la Torre et al., 2003) and the UV-resistant Deinococcus sp. (Hirsch et al., 1988, de la Torre et al., 2003). However, sequences matching other extreme-tolerant species such as Rubrobacter sp. as well as more temperate members such as Patulibacter sp. and Rubellimicrobium sp. again suggest the community reflects a mixture of moderate and extremophilic microbial species. As with other studies of endolithic habitats, several sequences were $<97 \%$ similar to the closest known species, instead forming groups of uncultured/uncharacterized endolithic bacteria that may serve very different functional roles than those of the closest relatives.

Carbon fixation from the active phototrophic community drives the carbon cycling; however, it appears that several of the other microbial members may be commensal to the phototrophs by contributing to the primary nutrient cycling within the endolithic system. The presence of Rubrivivax sp., purple non-sulfur phototrophic members of the $\beta$ proteobacteria, are capable of fixing $\mathrm{CO}_{2}$ and $\mathrm{N}_{2}$. Furthermore, the lichen-associated rhizobiales (LAR1) (Hodkinson and Lutzoni, 2009), which are non-phototrophic nitrogenfixing bacteria, may be an important source of nitrogen transfer to the endolithic near-surface phototrophs. Ammonia oxidation might also be important for $\mathrm{N}$ recycling within the endolithic system and could be mediated by the small archaeal community dominated by the Thaumarchaeota, including $\mathrm{Ni}$ trososphaera sp. Chroococcidiopsis sp. found in similar gypsum habitats were also found to fix nitrogen under certain conditions (Boison et al., 2004). The large diversity of heterotrophic bacteria observed to be growing in microcolonies as periphytes on the cyanobacteria or as biofilms on the anhydrite surfaces in close association with the carbon producing cyanobacteria supports the relationship between primary fixation of carbon followed by subsequent metabolism of labile organic carbon compounds. The abundance of lichenizing Verrucariales in the fungal community would also contribute to the direct exchange of nutrients between bacterial and fungal members, whereby the heterotrophically produced $\mathrm{CO}_{2}$ may also become a secondary carbon source for the cyanobacteria and algae (Johnston and Vestal, 1993).

\subsection{Activity of microbial community}

Since the molecular analysis of this endolithic community demonstrated the presence of many aerobic phototrophic organisms able to fix $\mathrm{CO}_{2}$ to make biomass, we traced the incorporation of atmospheric carbon into the microbial community. Using the radiocarbon composition of the microbial lipids, we were able to infer that the active microbial community turns over carbon surprisingly quickly given the extreme environmental conditions that were expected to signif- icantly limit turnover rates. The porous nature of the gypsum enables gas exchange with the atmosphere and thus the phototrophs likely incorporate carbon that was recently in equilibrium with the atmosphere. Due to exchange of $\mathrm{CO}_{2}$ between the rock and the atmosphere, we can use the ${ }^{14} \mathrm{C}$ from atmospheric weapons testing as a pulse label to estimate when the carbon was last in equilibrium with the atmosphere (i.e., Gaudinski et al., 2000). When the $\Delta^{14} \mathrm{C}$ of the PLFA was matched to the historical record of atmospheric ${ }^{14} \mathrm{C}$, the carbon within the cellular membranes of the viable microbial community was last in equilibrium with the atmosphere a decade ago. If the carbon cycling within the endolithic community was assumed to have a constant proportion of new production each year (i.e., model presented within $\mathrm{Zi}$ olkowski et al., 2013), then the rate of carbon turnover within the endolithic community is estimated at $12 \mathrm{yr}$. This implies that the rate of carbon cycling of the endoliths inhabiting the gypsum is far faster than previous estimates of carbon turnover in Antarctic endolithic communities (Bonani et al., 1988; Friedman et al., 1980), but in line with recent observations for endoliths in three different lithologies from the Atacama Desert (Ziolkowski et al., 2013). Additionally, these decadal rates of carbon turnover imply that there is minimal incorporation of carbonate carbon $\left(\Delta^{14} \mathrm{C}=-1000 \%\right.$ ) to the endolithic organisms.

To compare the rate of carbon turnover in the Arctic endoliths to previous studies, we converted our estimate of decadal turnover to an estimate of primary productivity $\left(\mathrm{g} \mathrm{C} \mathrm{m}^{-2} \mathrm{yr}^{-1}\right)$. To achieve this estimate, we made a few assumptions. First, we assumed that the rate of primary productivity equals the rate of the consumers and that there is no net productivity. The molecular data indicate that the relative abundance of primary producers was less than the total diversity of heterotrophic bacterial and fungal community members, which suggests that the primary productivity was sufficient to support a significant population of commensal microorganisms. Also, there is little evidence of long-term carbon accumulation within endolithic communities due to low rates of net primary productivity (Friedmann et al., 1993; Ziolkowski et al., 2013). Next, we assumed that the gypsum was $1 \%$ colonized (Wong et al., 2009) and $100 \mathrm{~g}$ samples were estimated to have a surface area of $15 \mathrm{~cm} \times 5 \mathrm{~cm}$. Finally, using our measurements of the $\Delta^{14} \mathrm{C}$ of the PLFA we assumed a turnover rate of $10 \mathrm{yr}$. Based on these assumptions, we calculated the rate of primary productivity to be $4.4 \mathrm{~g} \mathrm{C} \mathrm{m}^{-2} \mathrm{yr}^{-1}$, which is significantly higher than the previously reported primary productivity rates at nearby Devon Island $\left(0.8 \mathrm{~g} \mathrm{C} \mathrm{m}^{-2} \mathrm{yr}^{-1}\right.$; Cockell and Stokes, 2004) and Antarctic Dry Valleys $\left(1.2 \mathrm{~g} \mathrm{C} \mathrm{m}^{-2} \mathrm{yr}^{-1}\right.$; Friedman et al., 1993). In order for our calculated rate to be $1 \mathrm{~g} \mathrm{C} \mathrm{m}^{-2} \mathrm{yr}^{-1}$, the percent of the rock colonized would have a much lower density of colonization $(0.3 \%)$ or a much slower turnover rate $(40 \mathrm{yr})$. Our turnover rate $(10 \mathrm{yr})$ was determined from our ${ }^{14} \mathrm{C}$ measurements of the PLFA and a slower turnover rate (i.e., $40 \mathrm{yr}$ ) would require that the ${ }^{14} \mathrm{C}$ of 
the PLFA contain significantly more bomb carbon (i.e., $\Delta^{14} \mathrm{C}$ of $+500 \%$ ) (Nydal and Lövseth, 1983), which is well outside the analytical uncertainty of our radiocarbon measurements. Therefore, the only way our estimated rate of primary productivity could be the same as previous estimates is if only $0.3 \%$ of the rock was colonized. The percentage of colonized rock in the Arctic gypsum is likely to be significantly higher than $0.3 \%$ since the PLFA concentration of the Gypsum Hill endolithic community was two orders of magnitude higher than those in the Atacama Desert (Ziolkowski et al., 2013), where only $0.3 \%$ of the rock material sampled was colonized. Our estimate of primary productivity is on the same magnitude of $\mathrm{CO}_{2}$ fluxes from permafrost polygons (Oechel et al., 1995), which agrees with a previous study that found the rate of carbon fixation within the endolithic community matched nearby plant-based photosynthetic activity (Wong et al., 2009). Since most of the microbial activity occurs during the 6-month period between polar sunrise in the spring and the sunset in the autumn, primary productivity is likely limited to these months. While the activity of the heterotrophic microbes is not limited to when there is sun, the low temperatures of the winter likely limit the heterotrophic activity to the spring through autumn.

\subsection{Nutrient cycling and microbe-mineral interactions}

The activity of the microbial community relies not only moisture and light availability, but also the availability of nutrients. Previously, it has been demonstrated that the nutrient cycling within endolithic habitats relies on the close association of phototrophs and heterotrophs (Ferris and Lowson, 1997). Since some microbes, such as cyanobacteria, are able to fix nitrogen from the atmosphere, heterotrophs gain essential nutrients when consuming the organic material left by the phototrophs. Additionally, it has been established that endolithic communities inhabiting gypsum on nearby Devon Island gain their nutrients from allochthonous debris that concentrates on the outer gypsum surface and percolates into the endolithic habitat with wind and rainfall (Cockell et al., 2010). The dark color on the outer surface of the Gypsum Hill endolithic community suggests that a similar process is occurring at this site.

Trace metal distributions within endolithic habitats can also be used as a biomarker of microbial activity. Clear patterns of metal distribution associated with microbial activity have been observed in endolithic sandstone habitats on Ellesmere Island and the Antarctic Dry Valleys (Friedmann, 1982; Omelon et al., 2007). However, examination of the trace metal chemistry of this habitat showed little evidence of microbe-mineral interaction in this environment. The SEM micrographs of the Gypsum Hill community do not show evidence for mineral dissolution at the microbe-mineral interface. This lack of evidence of microbe-mineral interactions at Gypsum Hill is in agreement with the lack of evidence of biologically mediated sulfur remobilization of the Devon Island gypsum endolithic community (Cockell et al., 2010).

A possible explanation for the lack of clear evidence of microbe-mineral interactions is that any evidence has undergone physical weathering. Many polar endolithic communities inhabit more weather-resistant lithologies, such as sandstone (Sun and Friedmann, 1999). The endolithic community described here inhabits a host rock that is susceptible to weathering over time due to the soluble nature of gypsum. If the gypsum is in fact being weathered away over time, this would (a) erode away any evidence of microbial mineral interactions and (b) the endolithic community inhabiting the gypsum would also be weathered away. Since the endolithic habitat characterized here lacks evidence of microbe-mineral interaction and our data demonstrate that the viable microbial community contains carbon that was recently in equilibrium with the atmosphere, it is possible that the gypsum was recently weathered and this particular endolithic community was recently established. Algae and cyanobacteria often dominate newly exposed surfaces, and only once the biomass of these autotrophic communities has accumulated do lichens become part of the endolithic community (Hoppert et al., 2004). The presence of many highly specialized lichen in the phylogenetic analysis suggests that the mineral surface is not freshly weathered and that these weathering processes occurs slowly. It is possible that the rate of carbon turnover in an endolithic community is, at least partially, controlled by the rate of weather of the host rock. The application of radiometric dating is currently being investigated to elucidate the ages of rock surfaces mantling Gypsum Hill.

\section{Conclusions}

In summary, these detailed analyses reveal for the first time microbial activity and diversity of endolithic communities inhabiting gypsum in the high Arctic. A diverse but specialized community of bacteria, archaea, algae and lichenizing-fungi turn over carbon on decadal timescales, yet exhibit minimal microbe-mineral interactions, suggesting that these microorganism create a more dynamic ecosystem than previously suggested.

\author{
Supplementary material related to this article is \\ available online at http://www.biogeosciences.net/10/ \\ 7661/2013/bg-10-7661-2013-supplement.pdf.
}


Acknowledgements. This paper benefited greatly from the assistance of Jennie Kirby and Sheila Griffin. L. A. Ziolkowski, N. C. S. Mykytczuk and C. R. Omelon were funded by the CREATE Canada Astrobiology Training Program. Funding to L. A. Ziolkowski from the McMaster University Origins Institute. Logistical support provided to L. G. Whyte and C. R. Omelon by NRCan's Polar Continental Shelf Program. Funding support to G. F. Slater from NSERC Discovery Program and to C. R. Omelon from NSF\#ANS-0909482. We also wish to thank the McGill Arctic Research Station for ongoing support of our Arctic research programs. Synchrotron-based research described in this paper was performed at the Canadian Light Source, which is funded by the Canada Foundation for Innovation, the Natural Sciences and Engineering Research Council of Canada, the National Research Council Canada, the Canadian Institutes of Health Research, the Government of Saskatchewan, Western Economic Diversification Canada and the University of Saskatchewan.

Edited by: E. J. Javaux

\section{References}

AES: Eureka, Principle Station Data 79, Atmospheric Environmenta Service, Environment Canada, Downsview, Ontario, p. 25, 1984.

Altschul, S. F., Gish, W., Miller, W., Myers, E. W., and Lipman, D. J.: Basic local alignment search tool, J. Molecul. Biol., 215, 403-410, 1990.

Andersen, D. T., Pollard, W. H., and McKay, C. P.: The perennial springs of Axel Heiberg Island as an analogue for groundwater discharge on Mars, 9th International Conference on Permafrost, Fairbanks, Alaska, 2008.

Bahl, J., Lau, M. C. Y., Smtih, G. J. D., Vijaykrishna, D., Cary, S. C., Lacap, D. C., Lee, C. K., Papke, R. T., Warren-Rhodes, K. A., Wong, F. K. Y., McKay, C. P., and Pointing, S. B.: Ancient origins determine global biogeography of hot and cold desert cyanobacteria, Nat. Commun., 2, 163, doi:10.1038/ncomms1167, 2011.

Blackhurst, R. L., Jarvis, K., and Grady, M. M.: Biologicallyinduced elemental variations in Antarctic sandstones: a potential test for Martian micro-organisms, Int. J. Astrobiol., 3, 97-106, 2004.

Boison, G., Mergel, A., Jolkver, H., and Bothe, H.: bacterial life and dinitrogen fixation at a gypsum rock, Appl. Environ. Microbiol., 70, 7070-7077, 2004.

Bonani, G., Friedmann, E. I., Ocampo-Friedmann, R., McKay, C. P., and Woelfi, W.: Preliminary report on radiocarbon dating of cryptoendolithic microorganisms, Polarforschung, 58, 199-200, 1988.

Büdel, B., Weber, B., Kuhl, M., Pfanz, H., Sultemeyer, D., and Wessels, D.: Reshaping of sandstone surfaces by cryptoendolithic cyanobacteria: bioalkalization causes chemical weathering in arid landscapes, Geobiology, 2, 261-268, 2004.

Caporasso, J. G., Kuczynski, J., Stombaugh, J., Bittinger, K., Bushman, F. D., Costello, E. K., Fierer, N., Gonzalez Pena, A., Goodrich, J. K., Gordon, J. I., Huttley, G. A., Kelley, S. T., Knights, D., Koenig, J. E., Ley, R. E., Lozupone, C. A., McDonalds, D., Muegge, B. D., Pirrung, P. J., Reeder, J., Sevinsky, J. R., Turnbaugh, P. J., Walters, W. A., Widmann, J., Yatsunenko, T., Zaneveld, J., and Knight, R.: QIIME allows analysis of high-throughput community sequencying data, Nature Methods, 7, 335-335, 2010.

Cockell, C. S. and Stokes, M. D.: Widespread colonization by polar hypoliths, Nature, 431, 414, doi:10.1038/431414a, 2004.

Cockell, C. S., Osinski, G. R., Banerjee, N. R., Howard, K. T., Gilmour, I., and Watson, J. S.: The microbe-mineral environment and gypsum neogenesis in a weathered polar evaporite, Geobiology, 8, 293-2308, 2010.

Cole, J. R., Wang, W., Cardenas, E., Fish, J., Chai, B., Farris, R. J., Kulam-Syed-Mohideen, A. S., McGarrell, D. M., Marsh, T., Garrity, G. M., and Tiedje, J. M.: The Ribosomal Database Project: improved alignments and new tools for rRNA analysis, Nucleic Acids Res., 37, D141-D145, doi:10.1093/nar/gkn879, 2009.

Czimczik, C. I. and Welker, J. M.: Radiocarbon content of $\mathrm{CO}_{2}$ Respired from High Arctic Tundra in Northwest Greenland, Arct. Antarct. Alp. Res., 42, 324-350, 2010.

de la Torre, J., Goebel, B. M., Friedmann, E. I., and Pace, N. R.: Microbial diversity of cryptoendolithic communities from the McMurdo Dry Valleys, Antarctica, Appl. Environ. Microbiol., 69, 3858-3867, 2003.

de los Ríos, A., Wierzchos, J., Sancho, L. G., and Ascaso, C.: Acid microenvironments in microbial biofilms of Antarctic endolithic microecosystems, Environ. Microbiol., 5, 231-237, 2003.

de los Ríos, A., Sancho, L. G., Grube, M., Wierzchos, J., and Ascaso, C.: Endolithic growth of two Lecidea lichens in granite from continental Antarctica detected by molecular and microscopy techniques, New Phytol., 165, 181-190, 2005.

Dong, H., Rech, J. A., Jiang, H., Sun, H., and Buck, B. J.: Endolithic cyanobacteria in soil gypsum: occurrences in Atacama (Chile), Mojave (United States), and Al-Jafr (Jordan) Deserts, J. Geophys. Res.-Biogeo., 112, G02030, doi:10.1029/2006JG000385, 2007.

Dowd, S. E., Callaway, T. R., Wolocott, R. D., Sun, Y., McKeehan, T., Hagevoort R. G., and Edrington, T. S.: Evaluation of the bacterial diversity in the feces of cattle using 16S rDNA bacterial tag-encoded FLX amplicon pryosequencing (bTEFAP), BMC Microbiol., 8, 125, doi:10.1186/1471-2180-8-125, 2008 a.

Dowd, S. E., Sun, Y., Wolcott, R. D., Domingo, A., and Carroll, J. A.: Bacterial tag-encoded FLX amplicon pyrosequencing (bTEFAP) for microbiome studies: bacterial diversity in the ileum of newly weaned Salmonella-infected pigs, Foodborne Pathog. Dis., 5, 459-472, 2008b.

Ferris, F. G. and Lowson, E. A.: Ultrastructure and geochemistry of endolithic microorganisms in limestone of the Niagara Escarpment, Canadian J. Microbiol., 43, 211-219, 1997.

Friedmann, E. I.: Endolithic microbial life in hot and cold deserts, Origins Life Evol. B., 10, 223-235, 1980.

Friedmann, E. I.: Endolithic microorganisms in the Antarctic cold desert, Science, 215, 1045-1053, 1982.

Friedmann, E. I. and Ocampo-Friedmann, R.: Endolithic microorganisms in extreme dry environments: Analysis of a lithobiontic habitat, in: Current Perspectives in Microbiology, edited by: Klug, M. J. and Reddy, C. A., American Society of Microbiology, Washington, DC, 177-185, 1984.

Friedmann, E. I. and Ocampo-Friedmann, R.: A primitive cyanobacterium as pioneer microrganism for terraforming Mars, Adv. Space Res., 15, 243-246, 1995.

Friedmann, E. I., Friedmann, R. O., and McKay, C. P.: Adaptations of cryptoendolithic lichens in the Antarctic desert, in: 
Colloque sur les Ecosystemes Subantarctiques, edited by: Jouventin, P., Masse, L., and Trehen, P., Comite National Francais des Recherches Antarctiques, Paris, 65-70, 1981.

Friedmann, E. I., McKay, C. P., and Nienow, J. A.: The cryptoendolithic microbial environment in the Ross Desert of Antarctica: satellite-transmitted continuous nanoclimate data, 1984 to 1986 , Polar Biol., 7, 273-287, 1987.

Friedmann, E. I., Kappen, L., Meyer, M., and Nienow, J.: Long-term productivity in the cryptoendolithic microbial community of the Ross Desert, Antarctica, Microbial Ecol., 25, 51-69, 1993.

Gaudinski, J. B., Trumbore, S. E., Davidson, E. A., and Zheng, S.: Soil carbon cycling in a temperate forest: radiocarbon-based estiamtes of residence times, sequestration rates and partitioning of fluxes, Biogeochemistry, 51, 33-69, 2000.

Green, C. and Scow, K.: Analysis of phospholipid fatty acids (PLFA) to characterize microbial communities in aquifers, Hydrogeol. J., 8, 126-141, 2000.

Guckert, J. B., Antworth, C. P., Nichols, P. D., and White, D. C.: Phospholipid, ester-linked fatty acid profiles as reproducible assays for changes in prokaryotic community structure of estuarine sediments, FEMS Microbiol. Lett., 31, 147-158, 1985.

Hayes, J. M.: Fractionation of carbon and hydrogen isotopes in biosynthetic processes, in: Stable Isotope Geochemistry, edited by: Valley, J. W. and Cole, D., Reviews in Minerology and Geochemistry, 43, 225-227, 2001.

Hirsch, P., Hoffman, B., Gallikowski, C. C., Meys, U., Siebert, J., and Sittig, M.: Diversity and indentification of heterotrophs from Antarctic rocks of the McMurdo Dry Valleys (Ross Desert), Polarforschung, 58, 261-269, 1988.

Hodkinson, B. P. and Lutzoni, F.: A microbiotic survey of lichenassociated bacteria reveals a new lineage from the Rhizobiales, Symbiosis, 49, 163-180, 2009.

Hoppert, M., Flies, C., Pohl, W., Gunzi, B. and Schneider, J.: Colonization strategies of lithobiontic microorganisms on carbonate rocks, Environ. Geol., 46, 421-428, 2004.

Horath, T. and Bachofen, R.: Molecular Characterization of an Endolithic Microbial Community in Dolomite Rock in the Central Alps (Switzerland), Microbial Ecol., 58, 290-306, 2009.

Hughes, K. A. and Lawley, B.: A novel Antarctic microbial endolithic community within gypsum crusts, Environ. Microbiol., 5, 555-565, 2003.

Johnston, C. G. and Vestal, J. R.: Does iron inhibit cryptoendolithic communities?, Antarct. J. US, 21, 225-226, 1986.

Johnston, C. G. and Vestal, J. R.: Distribution of inorganic species in two Antarctic cryptoendolithic microbial communities, Geomicrobiol. J., 7, 137-153, 1989.

Johnston, C. G. and Vestal, J. R.: Biogeochemistry of oxalate in the Antarctic cryptoendolithic lichen-dominated community, Microbial Ecol., 25, 305-319, 1993.

Kappen, L., Friedmann, E. I., and Garty, J.: Ecophysiology of lichens in the dry valleys of Southern Victoria Land, Antarctica. I. Microclimate of the cryptoendolithic lichen habitat, Flora, 171, 216-235, 1981.

Lafleur, P. M., Humphrey, E. R., St. Louis, V. L., Myklebust, M. C., Papakyriakou, T., Poissant, L., Barker, J. D., Pilote, M., and Swystun, K. A.: Variation in peak growing season net ecosystem production across the Canadian Arctic, Environmental Science and Technology, 46, 7971-7977, 2012.
Levin, I. and Hesshaimer, V.: Radiocarbon - a unique tracer of global carbon cycle dynamics, Radiocarbon, 42, 69-80, 2000.

Matthes, U., Turner, S. J., and Larson, D. W.: Light attenuation by limestone rock and its constraint on the depth distribution of endolithic algae and cyanobacteria, Int. J. Plant Sci., 162, 263-270, 2001.

Naegler, T. and Levin, I.: Closing the radiocarbon budget 1945-2005, J. Geophys. Res., 111, D12311, doi:10.1029/2005JD006758, 2006.

Nienow, J. A. C., McKay, C. P., and Friedmann, E. I.: The cryptoendolithic microbial environment in the Ross desert of Antarctica: light in the photosynthetically active region, Microbial Ecol., 16, 271-289, 1988.

Norris, T. B. and Castenholz, R. W.: Endolithic photosynthetic communities within ancient and recent travertine deposits in Yellowstone National Park, FEMS Microbiol. Ecol., 57, 470-483, 2006.

Nydal, R. and Lövseth, K.: Tracing bomb ${ }^{14} \mathrm{C}$ in the atmosphere 1962-1980, J. Geophys. Res., 88, 3621-3642, 1983.

Oechel, W. C., Vourlitis, G. L., Hastings, S. J., and Bochkarev, S. A.: Change in Arctic $\mathrm{CO}_{2}$ flux over two decades: effects of climate change at Barrow, Alaska, Ecol. Appl., 5, 846-855, 1995.

Olsson, I.: The use of oxalic acid as a standard, Radiocarbon Variations and Absolute Chronology, 1970.

Omelon, C. R.: Endolithic Microbial Communities in Polar Desert Habitats, Geomicrobiol. J., 25, 404-414, 2008.

Omelon, C. R., Pollard, W. H., and Ferris, F. G.: Environmental controls on microbial colonization of high Arctic cryptoendolithic habitats, Polar Biol., 30, 19-29, 2006.

Omelon, C. R., Pollard, W. H., and Ferris, F. G.: Inorganic species distribution and microbial diversity within high Arctic cryptoendolithic habitats, Microbial Ecol., 54, 740-752, 2007.

Parnell, J., Lee, P., Cockell, C. S., and Osinski, G. R.: Microbial colonization in impact-generated hydrothermal sulphate deposits, Haughton impact structure, and implications for sulphates on Mars, International J. Astrobiol., 3, 247-256, 2004.

Pointing, S. B., Chan, Y., Lecap, D. C., Lau, M. C. Y., Jurgens, J. A., and Farrell, R. L.: Highly specialized microbial diversity in hyper-aric polar desert, P. Natl. Acad. Sci., 106, 19964-19969, 2009.

Pollard, W., Haltigin, T., Whyte, L., Niedergerger, T., Andersen, D., Omelon, C., Nadeau, J., Eccelstone, M., and Lebeuf, M.: Overview of analogue science activities at the McGill Arctic Research Station, Axel Heiberg Island, Canadian High Arctic, Planet. Space Sc., 57, 646-659, 2009.

Pruesse, E., Peplies, J., and Glöckner F.O.: SINA: accurate highthroughput multiple sequence alignment of ribosomal RNA genes, Bioinformatics, 28, 1823-1829, 2012.

Santos, G. M., Southon, J. R., Griffin, S., Beaupre, S. R., and Druffel, E. R. M.: Ultra small-mass AMS ${ }^{14} \mathrm{C}$ sample preparation and analyses at KCCAMS/UCI Facility, Nucl. Instrum. Meth. B, 259, 293-302, doi:10.1016/j.nimb.2007.01.172, 2007.

Sherwood, A. and Presting, G.: Universal primers amplify a 23S rDNA plastid marker in eukaryotic algae and cyanobacteria, J. Phycol., 43, 605-608, 2007.

Sigler, W. V., Bachofen, R., and Zeyer, J.: Molecular characterization of endolithic cyanobacteria inhabiting exposed dolomite in central Switzerland, Environ. Microbiol., 5, 618-627, 2003.

Sterflinger, K.: Fungi as geologic agents, Geomicrobiol. J., 17, 97$124,2000$. 
Steven, B., Pollar, W. H., Greer, C. W., and Whyte, L. G.: Microbial diversity and activity through a permafrost/ground ice core profile from the Canadian high Arctic, Environm. Microbiol., 10, 3388-3403, 2008.

Stuiver, M. and Polach, H. A.: Discussion; reporting of C-14 data, Radiocarbon, 19, 355-363, 1977.

Sun, H. J. and Friedmann, E. I.: Growth on geological time scales in the Antarctic cryptoendolithic microbial community, Geomicrobiol. J., 16, 193-202, 1999.

Tamura, K., Peterson, D., Peterson, N., Stecher, G., Nei, M., and Kumar, S.: MEGA5: Molecular Evolutionary Genetics Analysis using Maximum Likelihood, Evolutionary Distance, and Maximum Parsimony Methods, Molecul. Biol. Evol., 28, 2731-2739, 2011.

Vestal, J. R.: Carbon metabolism of the cryptoendolithic microbiota from the Antarctic desert, Appl. Environ. Microbiol., 54, 960965, 1988a.

Vestal, J. R.: Primary production of the cryptoendolithic microbiota from the Antarctic desert, Polarforschung, 58, 193-198, $1988 \mathrm{~b}$.

Vestal, J. R., Federle, T. W., and Friedmann, E. I.: The effects of light and temperature on antarctic cryptoendolithic microbiota in vitro, Antarct. J. US, 19, 173-174, 1984.

Walker, J. J. and Pace, N. R.: Phylogenetic Composition of Rocky Mountain Endolithic Microbial Ecosystems, Appl. Environ. Microbiol, 73, 3497-3504, 2007a.
Walker, J. J. and Pace, N. R.: Endolithic microbial ecosystems, Annu. Rev. Microbiol., 61, 331-347, 2007b.

Webb, S.: Sam's Microprobe Analysis Kit, Software and documentation available at: http://home.comcast.net/ sam_webb/smak. html, 2012.

White, D. C., Davis, W. M., Nickels, J. S., King, J. D., and Bobbie, R. J.: Determination of the sedimentary microbial biomass by extractable lipid phosphate, Oecologia, 40, 51-62, 1979.

Wierzchos, J., Ascaso, C., Sancho, L. G., and Green, A.: Ironrich diagenetic minerals are biomarkers of microbial activity in Antarctic rocks, Geomicrobiol. J., 20, 15-24, 2003.

Wierzchos, J., Ascaso, C., and McKay, C. P.: Endolithic cyanobacteria in halite rocks from the hyperarid core of the Atacama Desert, Astrobiology, 6, 415-422, 2006.

Wierzchos, J., Davila, A. F., Artieda, O., Cámara-Gallego, B., de los Ríos, A., Nealson, K. H., Valea, S., García-González, M. T., and Ascaso, C.: Ignimbrite as a substrate for endolithic life in the hyper-arid Atacama Desert: Implications for the search for life on Mars, Icarus, 224, 334-346, 2013.

Ziolkowski, L. A., Wierzchos, J., Davila, A. F., and Slater, G. F.: Radiocarbon evidence of active endolithic microbial communities in the hyper-arid core of the Atacama Desert, Astrobiology, 13, 607-616, doi:10.1089/ast.2012.0854, 2013. 